Pacific Northwest National Laboratory

Operated by Battelle for the U.S. Department of Energy

Under Contract DE-AC05-76RL01830

\title{
Facilitation of the Estuary/Ocean Subgroup for Federal Research, Monitoring, and Evaluation, FY08 Annual Report
}

\section{GE Johnson}

HL Diefenderfer

September 2008

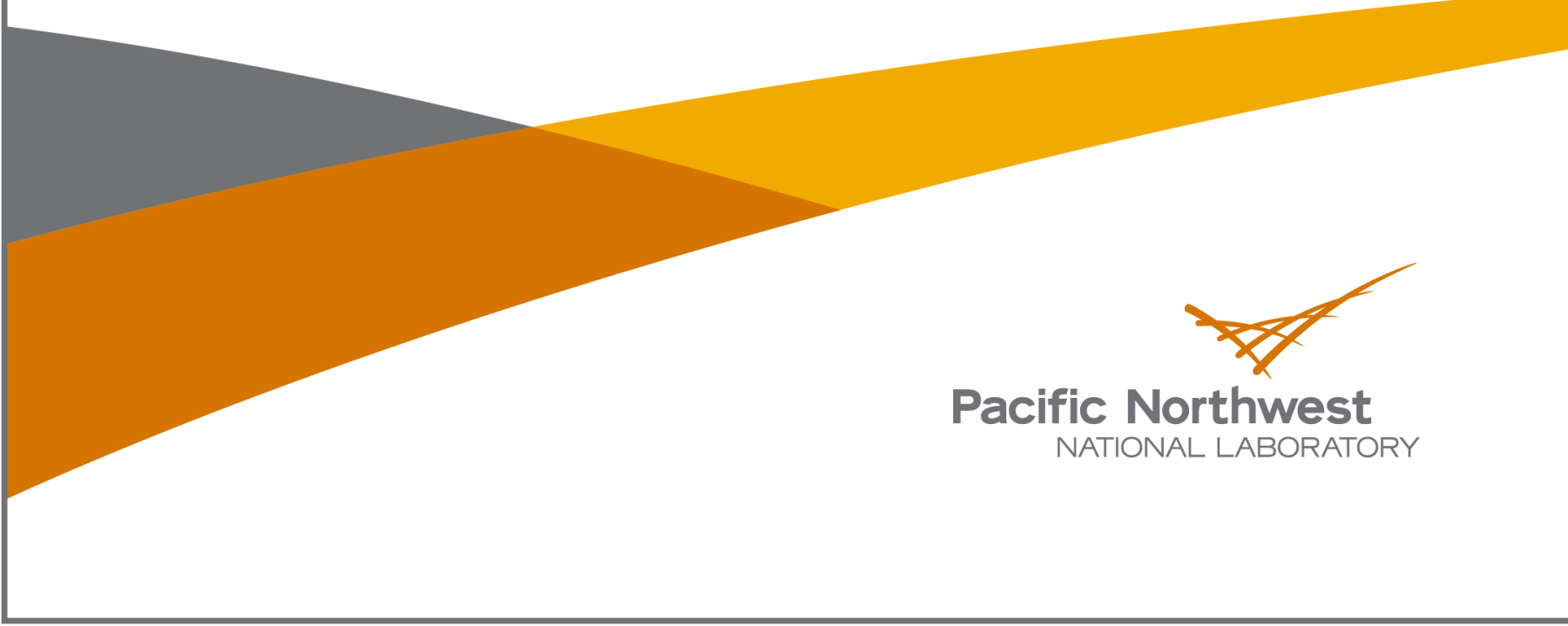




\title{
DISCLAIMER
}

This report was prepared as an account of work sponsored by an agency of the United States Government. Neither the United States Government nor any agency thereof, nor Battelle Memorial Institute, nor any of their employees, makes any warranty, express or implied, or assumes any legal liability or responsibility for the accuracy, completeness, or usefulness of any information, apparatus, product, or process disclosed, or represents that its use would not infringe privately owned rights. Reference herein to any specific commercial product, process, or service by trade name, trademark, manufacturer, or otherwise does not necessarily constitute or imply its endorsement, recommendation, or favoring by the United States Government or any agency thereof, or Battelle Memorial Institute. The views and opinions of authors expressed herein do not necessarily state or reflect those of the United States Government or any agency thereof.

\author{
PACIFIC NORTHWEST NATIONAL LABORATORY \\ operated by \\ BATTELLE \\ for the \\ UNITED STATES DEPARTMENT OF ENERGY \\ under Contract DE-AC05-76RL01830
}

This document was printed on recycled paper. 


\section{Facilitation of the Estuary/Ocean Subgroup for Federal Research, Monitoring, and Evaluation, FY08 Annual Report}

GE Johnson

HL Diefenderfer

September 2008

Prepared for the Bonneville Power Administration under an Agreement with the U.S. Department of Energy Contract DE-AC05-76RLO1830 



\begin{abstract}
The Estuary/Ocean Subgroup (EOS) is part of the research, monitoring, and evaluation (RME) effort that the Action Agencies (Bonneville Power Administration (BPA), U.S. Army Corps of Engineers, U.S. Bureau of Reclamation) developed in response to obligations arising from the Endangered Species Act as applied to operation of the Federal Columbia River Power System (FCRPS). The goal of the EOS project is to facilitate activities of the estuary/ocean RME subgroup as it coordinates design and implementation of federal RME in the lower Columbia River and estuary. In fiscal year 2008 (FY08), EOS project accomplishments included 1) subgroup meetings; 2) participation in the estuary work group of the Pacific Northwest Aquatic Monitoring Partnership; 3) project management via BPA's project tracking system, Pisces; 4) quarterly project status reports; and 5) a major revision to the Estuary RME document and its subsequent regional release (new version January 2008). Many of the estuary RME recommendations in this document were incorporated into the Biological Opinion on FCRPS operations (May 2008). In summary, the FY08 EOS project resulted in expanded, substantive coordination with other regional RME forums, a new version of the federal Estuary RME program document, and implementation coordination. This annual report is a FY08 deliverable for the project titled Facilitation of the Estuary/Ocean Subgroup.
\end{abstract}





\section{Preface}

The Bonneville Power Administration contracted with the Pacific Northwest National Laboratory (PNNL) to coordinate and facilitate the Estuary/Ocean Subgroup (EOS) (BPA Project No. 2002-077-00; Contract No. 26934, release 10). Initiated in 2002, the EOS is composed of members from:

- Bonneville Power Administration;

- Lower Columbia River Estuary Partnership (EP);

- National Oceanic and Atmospheric Administration National Marine Fisheries Service (NOAA Fisheries);

- PNNL’s Marine Sciences Laboratory;

- U.S. Army Corps of Engineers (USACE);

- and other agencies as necessary.

The EOS is one of multiple work groups in the federal research, monitoring, and evaluation (RME) effort developed in response to responsibilities arising from the Endangered Species Act as a result of operation of the FCRPS. The EOS is tasked by NOAA Fisheries and the Action Agencies (BPA, USACE, U.S. Bureau of Reclamation) to design and coordinate implementation of the federal RME plan for the lower Columbia River and estuary, including the plume. The purpose of project 2002-077-00 is to coordinate and facilitate activities of the EOS. For more information about the EOS, please contact Gary Johnson (503-417-7567). 



\section{Acknowledgments}

Important contributions to the EOS during fiscal year 2008 were made by Blaine Ebberts and Doug Putman (Portland District, USACE); Russell Scranton and Cathy Tortorici (NOAA Fisheries); Anne Creason, Jim Geiselman, and Tracey Yerxa (BPA); Chris Hathaway. Krista Jones, and Jill Leary (Estuary Partnership); Charlie Paulsen (Paulsen Environmental Research, Inc.); Tracey Hillman (BioAnalysts, Inc.); and Susan Ennor, Mike Parker, Nikki Sather, Jan Slater, and Ron Thom (PNNL). 



\section{Acronyms and Abbreviations}

$\begin{array}{ll}\text { AER } & \text { action effectiveness research } \\ \text { BA } & \text { before and after } \\ \text { BACI } & \text { before-after-control-impact } \\ \text { BiOp } & \text { Biological Opinion } \\ \text { BPA } & \text { Bonneville Power Administration } \\ \text { CRE } & \text { Columbia River estuary } \\ \text { CREC } & \text { Columbia River Estuary Conference } \\ \text { CREDDP } & \text { Columbia River Estuary Data Development Program } \\ \text { CREST } & \text { Columbia River Estuary Study Taskforce } \\ \text { EOS } & \text { Estuary/Ocean Subgroup } \\ \text { EP } & \text { Estuary Partnership } \\ \text { ERME } & \text { estuary research, monitoring, and evaluation } \\ \text { FCRPS } & \text { Federal Columbia River Power System } \\ \text { F\&W } & \text { Fish and Wildlife } \\ \text { FY08 } & \text { fiscal year 2008 } \\ \text { GIS } & \text { geographic information system } \\ \text { ISAB } & \text { Independent Scientific Advisory Board } \\ \text { ISEMP } & \text { Integrated Status and Effectiveness Monitoring Program } \\ \text { ISRP } & \text { Independent Scientific Review Panel } \\ \text { NED } & \text { Northwest Environmental Data network } \\ \text { NMFS } & \text { National Marine Fisheries Service } \\ \text { NOAA } & \text { National Oceanic and Atmospheric Administration } \\ \text { NPCC } & \text { Northwest Power and Conservation Council } \\ \text { PER } & \text { Paulsen Environmental Research } \\ \text { PNAMP } & \text { Pacific Northwest Aquatic Monitoring Partnership } \\ \text { PNNL } & \text { Pacific Northwest National Laboratory } \\ \text { RME } & \text { research, monitoring, and evaluation } \\ \text { RPA } & \text { Reasonable and Prudent Alternative } \\ \text { USACE } & \text { U.S. Army Corps of Engineers } \\ \text { WE } & \text { work element (Pisces) } \\ \text { WRDA } & \text { Water Resources Development Act } \\ & \end{array}$





\section{Contents}

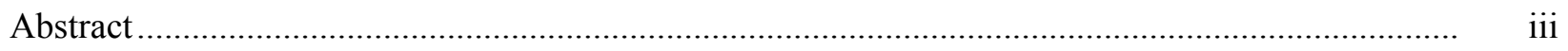

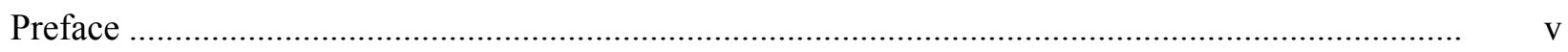

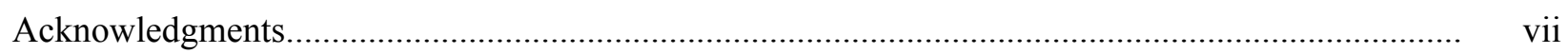

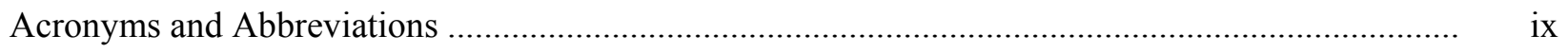

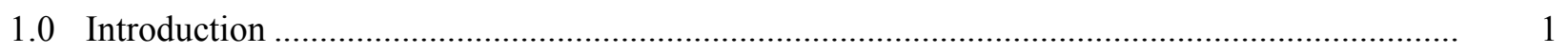

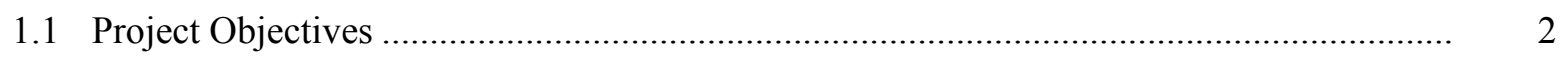

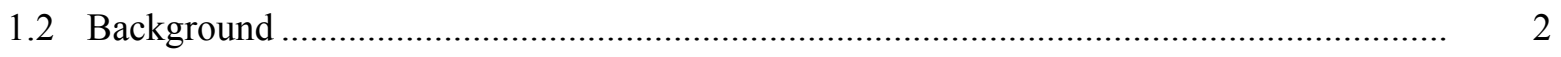

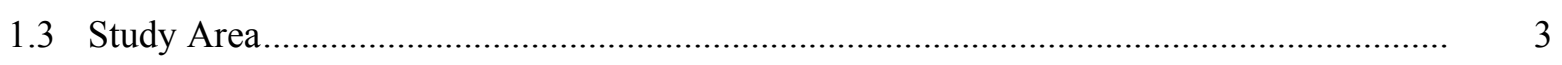

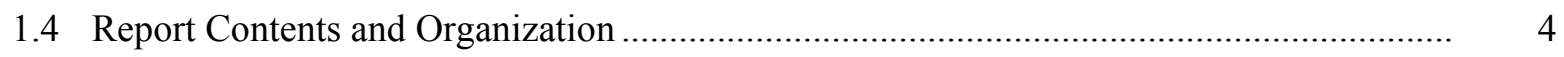

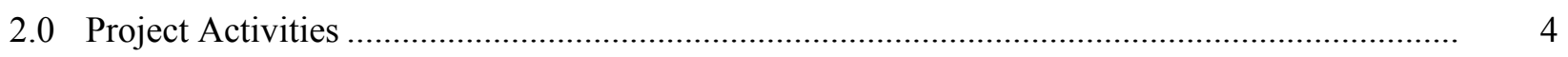

2.1 Work Element 118 - Coordination ............................................................................. 4

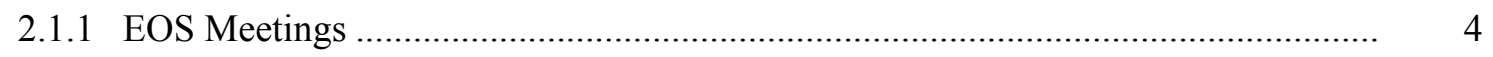

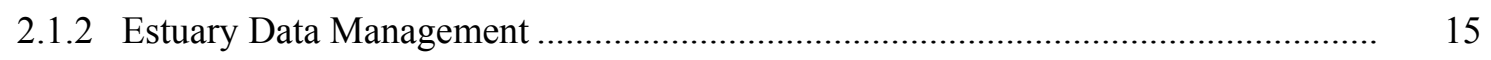

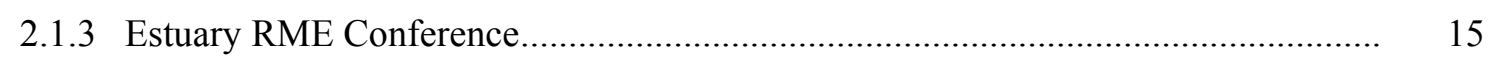

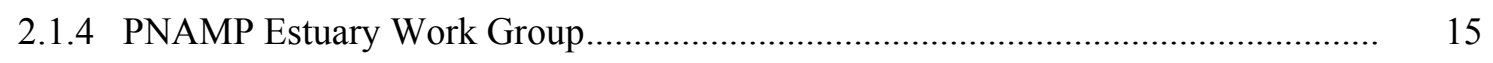

2.2 Work Element 119 - Manage and Administer Project................................................... 16

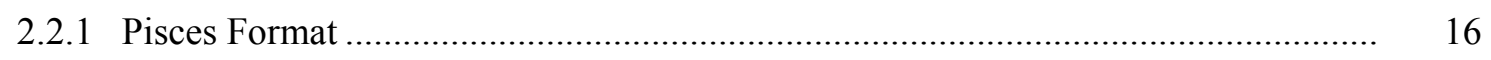

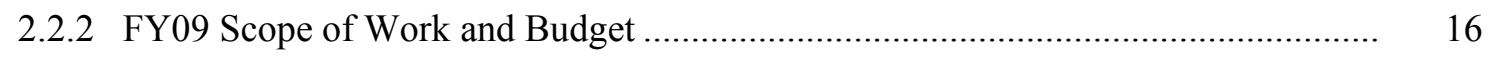

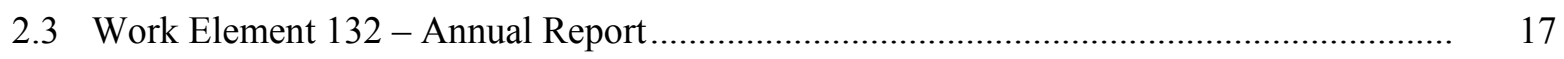

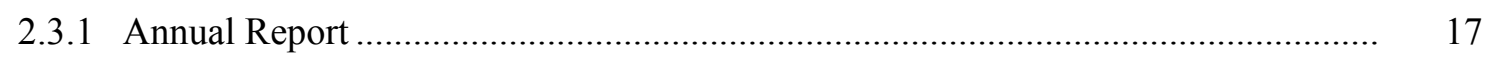

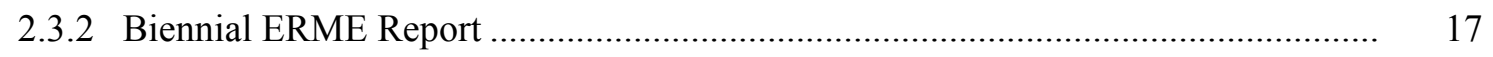

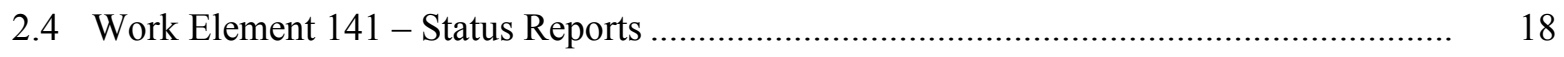

2.5 Work Element 174 - Produce Plan .................................................................................. 18

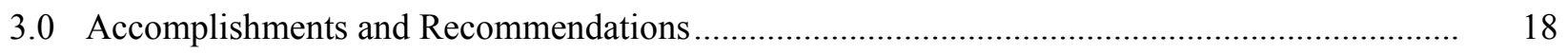

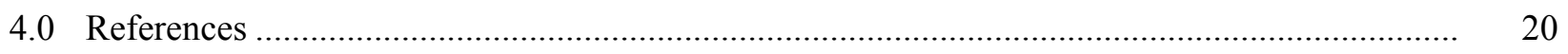

\section{Figures}

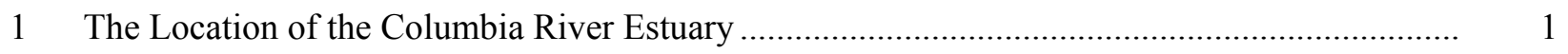

\section{Tables}

1 Intensively Monitored Restoration Sites by Restoration Type and Reach 



\subsection{Introduction}

This document is the annual report for fiscal year 2008 (FY08) for Project 2002-077-00, Facilitation of the Estuary/Ocean Subgroup (EOS). The EOS is part of the research, monitoring, and evaluation (RME) effort developed by the Action Agencies (Bonneville Power Administration [BPA], U.S. Army Corps of Engineers [Corps or USACE], U.S. Bureau of Reclamation) in response to obligations arising from the Endangered Species Act as a result of operation of the Federal Columbia River Power System (FCRPS). For the purposes of this report, the Columbia River estuary includes mainstem waters from Bonneville Dam down through the lower river and estuary into the river's plume in the ocean (Figure 1).

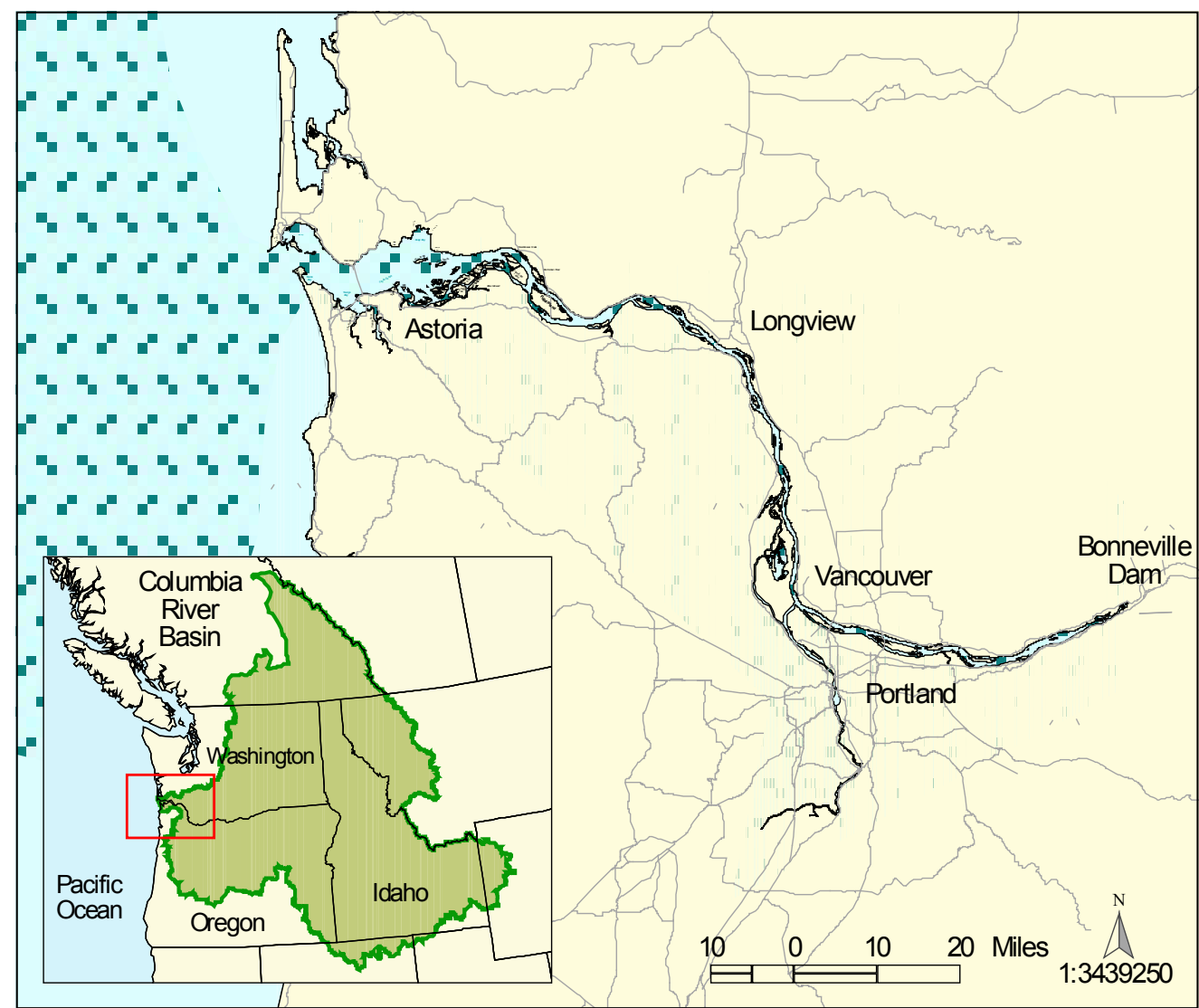

Figure 1. The Location of the Columbia River Estuary. The estuary includes mainstem waters from Bonneville Dam down through the lower river and estuary into the river's plume in the ocean.

The goal of the EOS project is to facilitate meetings and work products of the EOS as it coordinates implementation of the Estuary RME Program with the Pacific Northwest Aquatic Monitoring Partnership's (PNAMP's) estuary work group, the Northwest Power and Conservation Council's (NPCC's) Fish and Wildlife Program, federal RME parties, and other federal and non-federal entities conducting RME in the estuary. 


\subsection{Project Objectives}

The EOS project had the following objectives for FY08, designated by numbered categories in parentheses from the Pisces project tracking system as of October 1, 2007:

Coordination (118) - Continue facilitation of the EOS, including coordination with

a. RME Technical/Policy Oversight Group and Federal Caucus - Attend meetings and provide status reports as required.

b. PNAMP estuary work group - Attend and participate in work group meetings and assist in the development of coordinated estuary planning and monitoring approaches within PNAMP.

c. Northwest Environmental Data Network - Coordinate the estuary RME work with the developing data management effort for the basin-wide RME.

d. NPCC - Convene biennial estuary RME workshops to present new data, evaluate the conduct of the estuary RME program, exchange information, and provide input to the EOS.

Project Management and Administration (119) - Manage and administer the project according to BPA's project management and reporting system (Pisces), which is based on "Work Element/Milestones."

Annual Report (132) - Produce an annual report of project activities, including a detailed outline for a biennial estuary RME summary report incorporating adaptive management recommendations at the program level for submittal to the Action Agencies, estuary restoration project leaders, and other related entities (e.g., PNAMP).

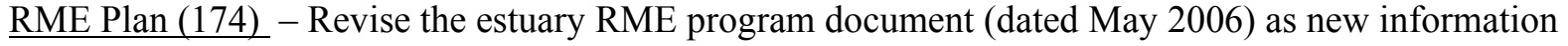
becomes available concerning RME in the Columbia River estuary.

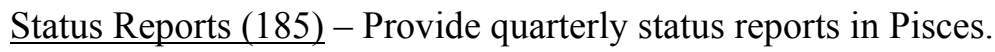

\subsection{Background}

The function of the Columbia River estuary ${ }^{1}$ in the life history of threatened and endangered salmonids is more than simply serving as a corridor for passage between the tributaries and the Pacific Ocean. The estuary provides habitat for multiple life history stages of salmon and steelhead, ranging from the rearing and feeding of fry, fingerlings, and smolts to the passage upstream of adults (Bottom et al. 2005). Use of estuary habitats by juvenile salmonids varies by species and life history stage (Rich 1920). Generally, the closer the natal stream is to the estuary and the smaller the juvenile migrant, the more likely it is that juveniles will use estuarine habitats as feeding, rearing, and refuge areas, i.e., as more than just a migration corridor (Dawley et al. 1986). Information on salmon biology and ecology in the Columbia River estuary can be found in reports by Bottom et al. (1984, 2005); Dawley et al. (1985a,b, 1986); Kirn et al. (1986); Ledgerwood et al. (1991); McCabe et al. (1983, 1986); McConnell et al. (1983); and Reimers and Loeffel (1967). In recognition of the estuary's importance to salmon population viability, the 2008 Biological Opinion (BiOp) on operation of the FCRPS called for the restoration of

\footnotetext{
1 The Columbia River estuary is defined as the tidally influenced portion of the river from Bonneville Dam to the plume. This is consistent with Bottom et al. (2005) and the Lower Columbia River Estuary Program (1999). Lower Columbia River tributaries are not part of the estuary RME study area.
} 
estuarine habitat as a pivotal action to avoid jeopardizing the continued existence of listed salmonid populations (NOAA Fisheries 2008), as well as comprehensive research, monitoring, and evaluation for listed salmon.

The Action Agencies and NOAA Fisheries established a process to develop a basin-wide plan to guide RME efforts for the tributaries, hydrosystem, and estuary/ocean. The process involves a Policy Oversight Group and six technical subgroups: Status Monitoring, Effectiveness Research, Hydrosystem, Hatchery/Harvest, Data Management, and Estuary/Ocean (EOS). One outcome of the federal RME process was a draft Basin-wide RME Plan (Jordan et al. 2003). In FY08, however, federal RME occurred in the context of ongoing litigation of the legal standing of the BiOps that originally created the RME process. Because of uncertainty in the outcome of the litigation, federal RME was instituted carefully with emphasis on expanded coordination with the states and tribes and other regional monitoring efforts.

During FY08, integration of federal BiOp RME efforts with PNAMP continued. This partnership is an assemblage of federal and state agencies and Tribes whose goal is "...to coordinate important scientific information at the appropriate scales needed to inform public policy and resource management decisions" (PNAMP 2004). Its geographic scope includes the Pacific Northwest and northern California. And, in FY05, PNAMP coordination work was extended from Columbia River tributary watersheds into lower river and estuary habitats.

Overall in FY08, EOS RME activities focused on revision and implementation of the federal Estuary RME Program. This document is the annual report of activities and accomplishments for the EOS project 2002-077-00 in FY08. Previous annual reports were submitted for FY05, FY06, and FY07 (Johnson 2005, Johnson 2006, Johnson and Diefenderfer 2007, respectively)

\subsection{Study Area}

A number of publications provide descriptive information about the Columbia River estuary:

- the Salmon at River's End report by Bottom et al. (2005)

- Fresh et al.'s (2005) Role of the Estuary in the Recovery of Columbia River Basin Salmon and Steelhead

- the Biological Assessment for the Columbia River Channel Improvements Project by the U.S. Army Corps of Engineers (2001)

- the RPA Action 158 action plan by Berquam et al. (2003) and the RPA Action 159 habitat restoration report by Johnson et al. (2003)

- the NPCC's sub-basin plan for the estuary (Lower Columbia River Estuary Partnership and Lower Columbia Fish Recovery Board 2004a; 2004b).

Important earlier compendiums include the following:

- The Columbia River Estuary and Adjacent Ocean Waters by Pruter and Alverson (1972)

- "Columbia River Estuary" in Changes in Fluxes in Estuaries: Implications from Science to Management by Dyer and Orth (1994) 
- Columbia River: Estuarine System by Small (1990), which contains reviews of earlier work supported by the Columbia River Estuary Data Development Program (CREDDP) on physical and biological processes (CREDDP 1984a, 1984b).

\subsection{Report Contents and Organization}

The following sections of this FY08 annual report for the EOS project describe project activities, summarize accomplishments, and provide recommendations for FY09. The sections on activities and accomplishments are organized by the work elements listed previously under project objectives (Section 1.1).

\subsection{Project Activities}

EOS project activities during FY08 included coordination efforts; project management and administration; project status reporting; and production of the Estuary RME Plan, as described in the following sections for each work element (WE).

\subsection{Coordination (WE 118)}

Meetings, data management, conference planning, and PNAMP estuary work group activities required coordination.

\subsubsection{EOS Meetings}

The EOS met four times in FY08: first on November 16, 2007 and, in 2008, on January 10, February 14, and March 18. A condensed summary of key discussions that occurred during the EOS meetings is provided below. This material is based on meeting notes prepared by Johnson and Diefenderfer and submitted to EOS members for review and comment after each meeting.

\subsubsection{Meeting Highlights - November 16, 2007}

Highlights of the meeting on November 16, 2007, follow. The participants were Jill Leary and Krista Jones (EP); Cathy Tortorici (NOAA Fisheries); Tracy Yerxa, Jim Geiselman, Anne Creason (BPA); Blaine Ebberts (USACE); and Gary Johnson and Heida Diefenderfer (PNNL). The meeting's objectives were to 1) discuss updates on RME-related activities, and 2) discuss revisions to the Estuary RME Plan. Leary introduced Krista Jones, the new Monitoring Coordinator for the Estuary Partnership.

\section{Updates}

BiOp Remand - The draft FCRPS BiOp was released by the National Marine Fisheries Service (NMFS) in October 2007. A meeting with the judge on the draft is expected in December 2007, and signing of the Record of Decision is expected in January 2008. The BiOp contains RME action items that refer to implementation of the Estuary RME (ERME) Program document. Yerxa said that the BPA estuary habitat restoration projects will go through the EP's Science Work Group process. Ebberts added 
that estuary habitat projects funded by USACE will go through respective Corps processes. Yerxa cautioned that Braun (Corps North Pacific Division) did not want to make any funding commitments in the ERME document. Tortorici recommended that the ERME document indicate which parts of the ERME Program the Action Agencies are implementing in response to the BiOp. The group agreed to incorporate the Reasonable and Prudent Actions (RPAs) dealing with estuary RME in the next draft of the ERME Program document (e.g., RPAs 58, 59, 69, 61, 71, 72, and 73). Tortorici does not expect the BiOp to call out the comprehensive coordination and synthesis that are needed in the estuary and described in the ERME Program document. The BiOp will likely be implemented whether or not a lawsuit is filed, unless the judge issues an injunction.

Federal RME - Comments were received on the 2003 Grand RME Plan (Jordan et al. 2003); after it had been finalized. The Action Agencies will consider revising the Grand RME Plan when the BiOp is released. Tortorici mentioned that she transmitted the ERME Program document to Kratz at the Northwest Fisheries Science Center; Kratz is working on the broad federal RME planning effort. Geiselman said that the intent is to revive the federal RME planning group and determine the role of the grand federal RME process.

Northwest Environmental Data Network (NED) - Leary reported that NED is alive but needs more participants; it is a way for groups without established data management to get data out to the region. A Portal Steward is needed. The new geographic information system (GIS) staff member at the EP, Keith Marcoe, will be attending NED meetings. The EP's goal is to have all of its data available through a portal (e.g., the T-sheets and H-sheets, funded cooperatively by the EP/BPA/Corps/NOAA, should be done by the end of the year). Geiselman reported that last January, a new Regional Information Management Strategy group began meeting to develop a framework; it became Columbia Basin centric and was picked up by the NED.

PNAMP Estuary Group - Ebberts and Johnson attended the recent meeting of this group in Olympia, Washington. Several topics of interest to the EOS were discussed. 1) The Puget Sound Partnership is up and running; Sarah Brace is the manager for RME. 2) When the new version of the Monitoring Protocols Manual for Columbia River Estuary (CRE) habitat restoration projects is ready in early 2008, it will be reviewed under the PNAMP process, likely by their Effectiveness Monitoring Committee. 3) RME project/program inventory produced an Access database that Johnson will mine to develop a list specific for estuary RME. This will be useful to both the EOS and the PNAMP estuary group. Tortorici noted that one of the main purposes of PNAMP is coordination across multiple estuaries, e.g., Skagit in Puget Sound, CRE, Salmon River estuary, and South Slough in Coos Bay. Diefenderfer added that the adaptive management processes being developed for EP and Corps estuarine habitat restoration programs include coordination and exchange of information and experiences across multiple estuaries.

NPCC Fish and Wildlife Program Amendment Process - Johnson asked what effect, if any, the NPCC's amendment process would have on ERME. The amendments are usually fairly general. It is not clear yet if the amendments will incorporate specific actions from the BiOp. The amendment process is in its early stages. The NPCC convened a Science-Policy Exchange meeting (www.nwcouncil.org/fw/program/2008/amend) that showcased the estuary/ocean in one of the four halfday segments. BPA implements much of the BiOp activity through the Fish and Wildlife (F\&W) Program, but there will be a limited amount of money above the F\&W Program cap to address the BiOp. 
Columbia River Estuary Conference (CREC) - It is time to put together the steering committee and all EOS members were invited. Dates were discussed with the goal of avoiding conflicts with 1) the fish research season and 2) the Western Division American Fisheries Society meeting in Portland in May. Ebberts reported that the Corps will include CRE talks at the Western Division of the American Fisheries Society (AFS) meeting, which is expected to have an ecosystem and RME focus. The EOS felt that the CREC's format should be invited summary/overview talks, as it was in 2006.

T- and H-Sheets - Leary reported that The Ecosystem Classification System for the CRE is expected to be complete by the end of the year. The T-sheets will be the subject of a workshop in March; there was a workshop recently on the H-sheets. The EP will house the available T-and H-sheets on its website. Leary said that the U.S. Geological Survey has a hyperlink to the bathymetry information it is compiling from the Corps, NOAA, etc. Ebberts commented that there is and will continue to be a lot of data to coordinate, manage, and disseminate.

Water Resources Development Act (WRDA) - Ebberts reported that a new WRDA passed in October 2007. It increases the cap for Corps estuary research from $\$ 10$ million to $\$ 25$ million.

Tagging Requirements Meeting - Geiselman alerted the EOS about an Independent Scientific Advisory Board (ISAB)/Independent Scientific Review Panel (ISRP) effort to review tagging requirements for various studies, e.g., smolt survival. The BPA, Corps, Columbia River Inter-Tribal Fish Commission, NPCC, etc. would be involved in this effort.

\section{Estuary RME Program Document}

At the direction of the EOS, and based on comments received by the EOS and other requested reviewers of the ERME Program document, Johnson and Diefenderfer developed an extensively revised version of the plan. The revised plan was emailed to the EOS for review prior to the meeting. EOS members made the following comments during the meeting and consensus was reached to release the revised ERME document to the public with a new version date once the in-meeting comments and any written comments received from the EOS by end of November has been addressed.

- Geiselman said the management questions that this would support require more focus, i.e., we'll need to resurrect the subset of management questions from previous drafts to guide sampling design, set spatial/temporal intensity, etc.

- Leary pointed out that "limiting factors," as defined in the Estuary Module, should be added to the glossary. The year of the ecosystem classification system needs to be changed to 2007.

- As mentioned above, Tortorici suggested that elements in the ERME document that are also in the draft BiOp be noted as such.

ACTION ITEM: Johnson and Diefenderfer will incorporate the comments into a new version and release it in January 2008. 


\section{EOS Annual Report 2007}

Johnson mailed the annual report to the EOS in October 2007. He solicited comments, but received none. The report may be downloaded at the BPA Environment, Fish, and Wildlife Publications website (http://www.efw.bpa.gov/searchpublications/); search for project 200207700.

\section{Role of the Estuary/Ocean Subgroup}

There was a consensus, led by Yerxa, Tortorici, and Leary, that the EOS was useful, but that it was time to shift its focus to the implementation phase for ERME. Examples of this focus might include the following:

- It is incumbent upon the EOS to track the implementation of elements of the ERME Program and note gaps in coverage.

- Guidance is needed on prioritization of Action Effectiveness Research in the estuary. (This will be the main agenda item for the next EOS meeting.)

- The EOS membership could conceivably be expanded to deal with RPA 60 - Monitor and Evaluate Habitat Actions in the Estuary.

- The EOS might lead in the development of periodic synthesis reports on RME in the CRE.

Overall, the role of the EOS has evolved to facilitate implementation of the ERME Program by providing technical support to resolve implementation issues, track progress, assess gaps in coverage, and coordinate implementation by the appropriate agencies.

\section{Next Meeting}

The next EOS meeting will focus Action Effectiveness Research (AER) because implementers need guidance on prioritizing the use of limited AER funds for restoration projects. Diefenderfer noted that this issue was addressed during the Corps' effort to develop the Monitoring Protocols Manual for habitat restoration projects in the CRE. Leary said AER guidance was needed in the Estuary Partnership's Habitat Restoration Program. One issue is the varying levels of monitoring expertise among project sponsors. Tortorici suggested someone compile a list of ongoing and planned restoration projects in the estuary - identify the universe of projects - then work to develop AER priorities. Yerxa offered that we needed AER to be organized and prioritized by type of project.

\subsubsection{Meeting Highlights - January 10, 2008}

Highlights of the meeting on January 10, 2008, follow. The meeting participants included: Chris Hathaway, Jill Leary, and Krista Jones (EP); Tracy Yerxa and Anne Creason (BPA); Blaine Ebberts and Doug Putman (USACE); and Gary Johnson and Heida Diefenderfer (PNNL). The meeting objective was to prioritize AER-monitored indicators, project types, and reaches in the CRE. Leary introduced Chris Hathaway, long-time EP staffer, as the new Director of Stewardship and Technical Programs. 


\section{Estuary RME Document}

Johnson handed out a pre-clearance release of the ERME Program document. It is a completely revamped version that incorporates comments from the last three years. The EOS should review and provide comments by January 26, 2008. Once cleared through PNNL's review process, the document will be released to the region. Ebberts, Leary, and Yerxa offered to post the plan on their respective websites. Ebberts proposed it was time to disseminate the document and solicit other agencies for funding for particular items. Leary suggested that we make the PNAMP Estuary Group aware of the document.

ACTION ITEM: Johnson will send the ERME Program document to Bayer for dissemination to the PNAMP Estuary Group.

Johnson offered that the EOS should focus a meeting in the near future on the Action Plan in the ERME Program document; it is time for implementation. Maybe this should be done after the EOS attends to the AER business.

\section{BiOp Update}

The draft FCRPS BiOp was released by NMFS in October 2007. Judge Redden has been holding conferences with the parties in the litigation. He sent the parties a comment letter in December. The Action Agencies are considering a response. The next milestone is a revised BiOp in March 2008.

\section{Action Effectiveness Research Discussion}

Purpose - Yerxa explained that BPA wants to intensively monitor the effectiveness of the additional habitat restoration projects it funds in the estuary through the EP (BPA Project No. 2003-011-00). The purpose of this agenda item is to prioritize monitored indicators and restoration projects for this new, long-term AER. (According to the draft BiOp, "long-term" means from 2008-2017.) Ebberts noted that this topic is germane for the Corps and others estuary-wide.

AER Guidance in the ERME Program Document - Diefenderfer provided a brief description of the AER elements in the ERME Program document. There is guidance on sampling design and monitored indicators. AER is linked to the Conceptual Ecosystem Model and the habitat opportunity, capacity, and realized function concepts of Simenstad and Cordell. Proper controls in the statistical sense are not necessary. However, reference sites are needed as end points to compare to the restoration site. The monitored indicator(s) will depend on the site and type of restoration. Also, the ERME Program document has a description of intensive versus extensive monitoring for integrated status and trends and action effectiveness monitoring. Ebberts said such integration was the Corps' intent. Leary said the same was true for the EP; e.g., some of their status and trends monitoring for the Ecosystem Monitoring project (BPA No. 2003-007-00) occurs at AER reference sites.

Portland District Strategy and Monitoring Protocols - Ebberts noted that the Portland District is developing an adaptive management plan for its habitat restoration program in the CRE. After the plan has been approved by District managers and implementation has begun, they intend to share it other regional Corps districts and national Corps headquarters. The adaptive management plan will be a chapter in the Cumulative Effects Study 2007 annual report (Johnson and Diefenderfer 2008). 
ACTION ITEM: Johnson will send the report to the EOS when it is ready in February 2008.

Adaptive management requires monitoring data that are comparable across projects and years. Therefore, the District funded work to develop effectiveness monitoring protocols and encourages their use by others monitoring in the CRE. Leary pointed out that the EP requires practitioners to use the District's protocols. Diefenderfer said a new version of the protocols should be released in February 2008.

ACTION ITEM: Johnson will send the protocols to the EOS when they are ready in February 2008.

ACTION ITEM: Diefenderfer and Jones will compare protocols for vegetation planting success between the District's protocols and the ones used at the Sandy River delta.

AER for EP Restoration Projects Funded by BPA - To foster discussion, Leary provided a handout of different tidal reconnection or vegetation planting projects and possible monitored indicators. Jones invited comments and asked that they be sent to her by January 26, 2008. The EOS had a lively discussion about intensive and extensive monitoring. We noted that the indicators to monitor depend on the site and restoration objectives; i.e., the core indicators may not all be applicable at a given site. At the beginning of a project, it is important to make science-based decisions about what to monitor and when. The EOS decided that a matrix showing what is currently being monitored and where it is being monitored is needed to provide input to the BPA and EP on intensive effectiveness monitoring at selected restoration sites.

ACTION ITEM: Johnson and Diefenderfer will develop a matrix of monitored indicators by restoration site by time (what, where, when) for all AER work in the CRE for the next EOS meeting.

\section{Conferences}

Talks pertinent to estuary RME will be presented at Pacific Estuarine Research Society in Newport, Oregon, in late February and at the Western Division AFS meeting in Portland, Oregon, in early May.

\section{Next Meeting}

The next EOS meeting will focus on the Effectiveness Monitoring Matrix to follow up on the January 10 meeting. The meeting is scheduled for February 14, 2008 at PNNL's Portland office.

\subsubsection{Meeting Highlights - February 14, 2008}

Highlights of the meeting on February 14, 2008, follow. The participants included: Chris Hathaway, Jill Leary, and Krista Jones (EP); Tracy Yerxa and Anne Creason (BPA); Blaine Ebberts (USACE); and Gary Johnson and Heida Diefenderfer (PNNL). The purpose of the meeting was to recommend CRE restoration projects for intensive AER in 2008 and beyond. 


\section{ERME Program Document}

Hard copies of the ERME Program document were distributed. It is ready for regional release. The document PDF will be sent to the EOS with the meeting notes. Johnson reiterated that the EOS should focus on RME implementation.

ACTION ITEM: Ebberts, Leary, and Creason will post the PDF on their respective websites.

ACTION ITEM: Johnson will send the ERME Program document to Bayer for dissemination to the PNAMP Estuary Group.

ACTION ITEM: Johnson will make a brief presentation on the ERME at the next Science Work Group meeting (February 26).

\section{Updates}

$\underline{B i O p}-$ Not discussed.

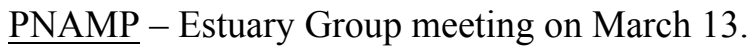

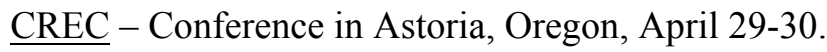

Monitoring Protocols Manual - The manual is due from PNNL/NOAA by the end of February. Diefenderfer noted that she will be seeking a focused review from Russell (CREST), Jones (EP), and Whiting (Trask and Associates).

\section{Action Effectiveness Research Discussion}

Purpose - The purpose of this agenda item is to continue efforts started during the last meeting to prioritize monitored indicators and restoration projects for the new, long-term AER effort.

Monitoring Matrix - A matrix of monitoring for action effectiveness in the CRE was handed out and discussion ensued to edit the projects (rows) and their attributes (columns). The current version will be sent to the EOS with the meeting notes.

ACTION ITEM: EOS will edit the matrix of monitored indicators by restoration site by time (what, where, when) for all AER work in the CRE; input is due March 7, 2008 to Johnson, who will incorporate input and distribute the updated matrix.

Johnson also handed out a set of maps showing monitoring sites and the temporal distribution of key monitored indicators by site. These maps are in the draft stage; they will be finalized when the monitoring matrix is updated in March 2008.

Extensive Versus Intensive Monitoring - Ebberts noted that the Cumulative Effects project team was working on this topic and would have guidance for the next EOS meeting. The Corps is including this concept in its adaptive management framework for habitat restoration in the CRE. They will be recommending monitored indicators for extensive and intensive types of monitoring. Diefenderfer noted 
that protocols for the higher-order metrics, which are not included in the protocols manual, will need to come from cited technical reports.

Plans for Intensive Monitoring - The EOS discussed projects where intensive monitoring is occurring or is planned to prioritize further additional intensive monitoring and Table 1 was developed.

Table 1. Intensively Monitored Restoration Sites by Restoration Type and Reach

\begin{tabular}{|c|c|c|c|c|c|c|c|c|}
\hline \multirow[b]{2}{*}{ Restoration Type } & \multicolumn{8}{|c|}{ Reach } \\
\hline & A & B & C & $\mathrm{D}$ & $\mathrm{E}$ & $\mathrm{F}$ & G & $\mathrm{H}$ \\
\hline Dike Breach & Sharnelle & & & & & & & \\
\hline Tidegate Installation & & $\begin{array}{l}\text { Julia Butler } \\
\text { Hanson }\end{array}$ & & & & & & \\
\hline Tidegate Replacement & Vera & $\begin{array}{l}\text { Julia Butler } \\
\text { Hanson }\end{array}$ & & & & & & \\
\hline Culvert Installation & & & & & & & & \\
\hline Culvert Removal & Ft Clatsop & & & & & & & \\
\hline Culvert Replacement & & Kandoll & & & & & & \\
\hline Culvert Enhancement & & & & & & & & Mirror Lk \\
\hline Pile Removal & & & & Coal Ck & & & & \\
\hline Revegetation & & & & & & Scappoose & $\begin{array}{l}\text { Sandy } \\
\text { Delta }\end{array}$ & \\
\hline $\begin{array}{l}\text { Elevation Modification } \\
\text { Creation }\end{array}$ & & & & Crims Is & & & & \\
\hline
\end{tabular}

The EOS recommended that the EP and BPA go forward with intensive monitoring for Fort Clatsop and Mirror Lake tidal reconnection projects. Monitoring revegetation work at the Sandy Delta and Scappoose Bottoms projects was discussed.

Yerxa stated that we should use 2017 as a planning horizon because that is the time outlined in the draft BiOp for federal actions.

Yerxa noted that the EOS should seek review of the plan for intensive monitoring from Geiselman et al. in the Federal RME process.

\section{Next Meeting}

The next EOS meeting will focus on the Effectiveness Monitoring Matrix to follow up on the February 14 meeting. The meeting is scheduled for April 10, 2008, 0900-1200 h at PNNL's Portland office.

\subsubsection{Meeting Highlights - March 18, 2008}

Highlights of the meeting on March 18, 2008, follow. The participants included: Gary Johnson and Heida Diefenderfer (PNNL); Chris Hathaway, Jill Leary, and Krista Jones (EP); Tracy Yerxa and Anne 
Creason (BPA); Tracy Hillman (BioAnalysts); and Charlie Paulsen (Paulsen Environmental Research [PER]). The purpose of the meeting was to recommend CRE restoration projects for intensive AER in 2008 and beyond.

Goals: The goals of the meeting were to confirm conceptual consistency between action effectiveness monitoring in tributary versus estuary habitats and provide recommendations for the EP's effectiveness monitoring effort.

Background: This meeting continues efforts from the last two EOS meetings (1/10/08 and 2/14/08) to prioritize monitored indicators and restoration projects that will be intensively monitored for action effectiveness during 2008 and beyond to 2017, the BiOp horizon. The immediate concern is thoughtful, scientific implementation of funding from BPA to the EP for action effectiveness monitoring in 2008. However, the EOS recognizes this is a broader issue encompassing all action effectiveness activities in the estuary and is treating it as such.

At the last EOS meeting, Yerxa noted that the EOS should seek review of the plan for intensive action effectiveness monitoring from Geiselman et al. in the federal RME process. Accordingly, Charlie Paulsen and Tracy Hillman, scientists heavily involved in tributary action effectiveness design, implementation, and analysis, were invited for consultation at the EOS meeting reported herein.

Objectives: 1) Provide an overview of tributary action effectiveness monitoring; 2) provide an overview of estuary AER, including the content in the ERME Program document, existing effectiveness monitoring protocols, the monitoring matrix, and proposed effectiveness monitoring for 2008; and 3) discuss and make recommendations for the EP's effectiveness monitoring effort.

\section{Tributary Effectiveness Monitoring}

Paulsen and Hillman described the tributary effectiveness monitoring that is part of federal RME in the Columbia basin. Effectiveness is measured by the change in survival of juvenile or adult salmon associated with habitat restoration actions. There has been some research on parr to smolt to adult survival using passive integrated transponder (PIT) data comparing survival among watersheds. The three main management questions in the tributaries are 1) Are salmon population sizes decreasing or increasing? 2) Are the primary limiting factors related to habitat conditions decreasing or increasing? 3) Are the management actions benefiting salmon populations?

Formal, coordinated effectiveness monitoring is just getting started. As part of the Integrated Status and Effectiveness Monitoring Program (ISEMP), there are intensively monitored watersheds in the Wenatchee/Entiat, Lemhi, and John Day basins where the key is to monitor smolts migrating out and adult salmon and/or steelhead migrating in. Most tributary watersheds have habitat restoration actions planned. In addition, hatchery reform and supplementation are planned for many populations.

Control and reference sites are defined the same in tributary and estuary habitat restoration - a control is a site like the restored site but nothing is changed, whereas a reference is a site like that which the restoration site is intended to become. A control site must have a salmon population in a habitat or watershed that is not touched. Because there is something going on in almost all watersheds to improve conditions for salmon in one form or another, a true control is hard to find. It also is tough to maintain a control over time for the purpose of an effectiveness evaluation. This means a design like the BACI (before-after-control-impact) is hard to implement at the population scale. Where a BACI design is not 
feasible, other approaches such as modeling or "levels of evidence" (correlative) approaches are being implemented in the tributaries.

In some cases, effectiveness monitoring in tributaries is occurring at two spatial scales: 1) project scale, comparing impact (treatment) sites to control or reference sites (BACI designs); and 2) population scale, measuring the status of populations before and after (BA) implementation of restoration actions (BA designs). Investigators make inferences through correlations between the project and population scale data.

In the tributaries, the primary habitat restoration actions are reconnecting off-channel habitats to rivers and increasing channel structure diversity. There are confounding factors, however, such as the introduction of coho salmon in Chinook salmon areas and changes in hatchery practices. Also, some watersheds have multiple actions while others have just one; this complicates effectiveness monitoring.

Diefenderfer asked if there was a periodic roll-up and synthesis of data from the various tributary AER projects. Hillman replied that systems were in place and others are being developed through the ISEMP for data management, analysis, and dissemination. He said they are applying principles of adaptive management in the upper Columbia basin recovery planning process.

Johnson wondered if formal monitoring protocols were in place. Hillman said they were and that, as a matter of fact, a special comparison study of different habitat protocols has been conducted (he'll send us a copy of the report).

\section{Estuary Effectiveness Monitoring}

Estuary/Ocean RME - Diefenderfer summarized AER in the estuary RME document (Johnson et al. 2008) that was recently released regionally. Estuary AER is designed to address RPA 60 in the draft BiOp. It provides guidance and direction for the EP's effectiveness monitoring effort. The Reference Site Study, by PNNL through the EP, is a key element of AER in the estuary (see bullet 1 under RPA 60). Not many locations make perfect reference sites; the goal is to have lateral connectivity with the mainstem Columbia River and low disturbance. Reference sites are stratified by reach. Eight hydrogeomorphic reaches have been designated for the 146 river miles between Bonneville Dam and the mouth. Paulsen and Hillman said hydrogeomorphic-based classifications are also implemented in the tributaries. Diefenderfer described the statistical design for AER for estuary restoration projects - the control chart method whereby the trajectory of a given monitoring indicator (e.g., sediment accretion) is toward the level of said indicator at the reference site with which the project is paired. Sampling is preferred before the action, but it is not mandatory. As in the tributaries, controls are not generally useful or practical at the population scale (because they cannot be maintained for long periods of time), but they have value at the reach or project scale. Hillman noted that in practice the standard deviation around the point estimate varies through time. Hillman asked if we had started to populate the control chart with data. No, not yet, but the EP's effectiveness monitoring effort will be applied to this cause.

Monitoring Protocols - Diefenderfer reported that the Effectiveness Monitoring Protocols Manual for the Columbia River and Estuary (Roegner et al. 2008) is nearing completion. The development team, part of the Corps' Cumulative Effects Study, intends to release the document before the Columbia River and Estuary Conference, April 29-30, 2008. The manual includes the following "core" indicators: hydrology (water surface elevation), water quality (salinity, temperature, dissolved oxygen), elevation (bathymetry, 
topography), landscape features, plant community (vegetation cover and composition), re-vegetation planting success, and fish community (species, temporal presence/absence, size structure). Higher order monitored indicators, such as salmon growth, are not included. Not all core indicators will be monitored at all sites because of differing project goals and monitoring budgets. The Cumulative Effects Study recommended extensive monitoring (many sites, few indicators) include hydrology, bathymetry, topography, and sediment accretion. The key will be to link the extensive monitoring of hydrology and sediment accretion with intensive monitoring of the plant and fish communities and other indicators through time. Paulsen noted that it will be important to do the roll-up of data derived from the various AER projects in the estuary.

Monitoring Matrix - Johnson presented a matrix of monitoring for action effectiveness in the CRE (included as an attachment in the original meeting notes). Tidal reconnection and re-vegetation are the most common types of restoration being undertaken. He also noted that the list of reference sites contained in the EP's Reference Site Study.

EP Effectiveness Monitoring for 2008 - Jones and Leary described the effectiveness monitoring effort noting that the EP is implementing an extensive Habitat Restoration Program that requires effectiveness monitoring. As part of this overall effort, the EP is working to implement habitat restoration and effectiveness monitoring mandated in the 2007 draft BiOp. Yerxa reminded the group that BPA is striving to implement RPA 60 - Monitor and Evaluate Habitat Actions in the Estuary and that, as part of this effort, Yerxa asked the EP to draft the document presented at this meeting. She emphasized that the proposed intensively monitored projects were subject to change based on review by Paulson and Hillman and the needs of a statistical design, and that additional projects could be added in later years as they come online to fill any identified gaps. Jones explained that the four projects the EP is proposing for intensive monitoring starting in 2008 (Mirror lake, Sandy delta revegetation, Scappoose bottomlands, and Fort Clatsop) had already been initial reviewed during the EOS meetings on January 10 and February14, 2008. Additional vetting occurred at the EP's Science Work Group meeting on February 26, 2008. The EP is integrating action effectiveness with their Ecosystem Monitoring Program, which a basically status and trend monitoring, to achieve cost savings and other efficiencies. The time frame for this effectiveness monitoring effort is 2008-2017, the stated period for the 2008 FCRPS BiOp.

\section{Discussion and Recommendations}

Geiselman joined the meeting briefly by phone. He commented on the EP's effectiveness monitoring effort, stating that he was concerned that the projects selected for monitoring did not have many restoration treatments, clear control/reference sites, and enough sampling years.

Paulsen noted that salmon performance in the estuary has moved away from juvenile and adult salmon survival to concentrate on the effects of habitat restoration on juvenile salmon growth, life history diversity, etc. This is inherently simpler than linking habitat improvements with survival improvements. Furthermore, he noted that it is difficult to prove that a particular habitat improvement action will directly affect juvenile or adult survival. If there a direct effect, however, it would be powerful support for habitat restoration. Only four studies in the literature have indicated such a linkage; none were in tidal freshwater or estuaries. Hillman and Paulsen agreed that because the BiOp calls for estuary habitat improvements and the AER will include habitat monitoring, the ERME Program is on the right track to address BiOp requirements. 
Diefenderfer commented that these long-term, intensively monitored projects are a great opportunity to reduce uncertainty in the outcome of habitat restoration actions in the estuary. Therefore, it is incumbent upon the practitioners to create and implement designs that will address questions experimentally and to plan for a substantial data management and data analysis effort once monitoring gets underway.

ACTION ITEM: Paulsen and Hillman will provide write-ups of their thoughts on 1) the four sites; 2) statistical design for AER at each, including appropriateness of reference sites; 3 ) monitored indicators at each site; 4) plans for data roll-up; 5) plans for determining the relationship between intensive and extensive monitoring; and 6) experiences and lessons learned implementing action effectiveness research in the tributaries. (These write-ups were included as Attachments 3 and 4 in the original meeting notes.)

In conclusion, the EOS along with Paulsen and Hillman confirmed the conceptual consistency between action effectiveness monitoring in tributary and estuary habitats. The group made the following recommendations for the EP's effectiveness monitoring effort:

- Proceed with monitoring at the four sites after incorporating comments from Paulsen and Hillman into the monitoring plans.

- Develop a time line for monitoring by indicator, including frequency and duration of sampling and data analysis for each site.

- Plan for and establish comprehensive data management system for intensively monitored sites, analogous to that for tributaries.

- Identify other categories of restoration projects (e.g., geographic locations, habitat types, restoration actions) that should receive intensive monitoring in out-years, pending project development/implementation and the total number of intensively monitored projects to be included in this BPA program.

- Consider incorporating a tagging component to monitor salmonid residence time and growth in restoring tidal wetlands; consider doing this in different habitat types/reaches of the estuary.

\subsubsection{Estuary Data Management}

This FY08 EOS objective was in stand-by mode pending the outcome of the regional data management initiative - NED (Northwest Environmental Data Network). NED will support the data management needs of PNAMP. NED's mission will involve regional data integration. The network will work to discover the data gaps, how best to share data, and to determine the quality of the data. In FY08, the EOS kept abreast of this data management effort, but did not perform any estuary data management activities.

\subsubsection{Estuary RME Conference}

During FY08, the EOS convened an inter-agency steering committee to host an Estuary RME Conference. Previously, the EOS had facilitated and participated in such an estuary RME conference in Astoria, Oregon, April 19-20, 2006. That event was called the Conference on Research, Monitoring, and Restoration in the Lower Columbia River, Estuary, and Nearshore Ocean. The proceedings (Johnson and Sutherland 2006) include copies of the presentations, abstracts, speaker biographies, and notes on the 
question/answer sessions. A conference website at http://cerc.labworks.org/ serves to make the activity publicly accessible. Proceedings of the conference (Johnson and Sutherland 2008) were collated and made available on the conference website. ...

About 150 scientists, policy-makers, resource managers, and the public attended the Columbia River Estuary Conference (CREC) during April 29-30, 2008 at the Liberty Theater in Astoria, Oregon. The overall purpose of this biennial conference series is to provide a forum to coordinate and exchange data and information on research, monitoring, and restoration efforts related to juvenile salmon in the lower Columbia River, estuary, and nearshore ocean. The 2008 conference was the fifth in the series with each event having a topical theme. Previous themes were Biological Integrity (1999), Habitat Conservation and Restoration (2001), Research Needs (2003), and Estuarine and Ocean Ecology of Juvenile Salmonids (2006). The 2008 conference theme was Ecosystem Restoration.

Research, monitoring, and restoration actions in the Columbia River from Bonneville Dam to the ocean plume have increased dramatically in the past five years in recognition of the importance of these ecosystems to the viability of Columbia River salmonid populations and other species. Many of these actions are included as mandates or recommendations in subbasin plans, recovery plans, biological opinions, and research reviews. Numerous agencies and non-governmental entities are engaged in this effort. Periodically sharing results, learning from other work, and providing a basis to continually improve our collective knowledge and decision-making are vital.

\subsubsection{PNAMP Estuary Work Group}

The PNAMP Estuary Work Group, which formed in FY05, met several times during FY08. Monitoring protocols were a main topic of interest. Johnson informed the group of the Effectiveness Monitoring Protocols Manual for the Columbia River Estuary (Roegner et al. 2008), as well as the ERME Program document. The PNAMP Estuary Work Group also is working with the broader PNAMP effort on a data dictionary and web-based data dissemination; both are relevant topics for Estuary RME.

\subsection{Project Management and Administration (WE 119)}

\subsubsection{Pisces Format}

During FY08, BPA continued to implement Pisces, the project tracking system. Accordingly, we provided input on Project 2002-077-00 to Pisces.

\subsubsection{FY09 Scope of Work and Budget}

PNNL developed and submitted the FY09 scope of work and budget for Project 2002-077-00 to BPA via Pisces in August 2008. Project work in FY09 will include the facilitation of the EOS (ongoing), assessing the benefits of habitat restoration (new), and helping with strategic planning for restoration (new). 


\subsection{Annual Report (WE 132)}

\subsubsection{Annual Report}

This document fulfills the annual report objective.

\subsubsection{Biennial ERME Report}

The EOS proposed the idea for a biennial report on RME work in the CRE under its ERME Program (Johnson et al. 2008). The purpose of the biennial report would be to summarize, synthesize, and evaluate new findings in the context of the major management questions. The biennial report would be a key part of the adaptive management process for RME in the CRE and build upon the Protocols for Monitoring Habitat Restoration Projects in the Lower Columbia River and Estuary (Roegner et al. 2008) sponsored by the Corps of Engineers. Agencies and non-governmental organizations including the National Park Service, CREST, LCREP, and Columbia Land Trust (CLT) are using these protocols to monitor restoration and reference sites and on this basis it is expected that comparable datasets will become available in coming years. A draft outline for the report (adapted and expanded from the FY06 Annual Report, Johnson 2006) is as follows:

Title: Research, Monitoring, and Evaluation in the Columbia River Estuary: Biennial Report

Chapter 1 - Introduction (why, when, where)

Purpose

Background

Study Area

Contents

Chapter 2 - Management Needs (what the RME work is intended to address, i.e., the drivers for the research and monitoring)

Introduction

Federal Estuary Program Goal and Objectives

Key federal management questions (link to BiOp ERME)

Federal RME Objectives (link to ERME Program document)

Chapter 3 - Research and Monitoring (describe what's being done to address management needs)

Introduction

Federal Agencies, Programs, and Funding Processes (Corps, BPA, through EP, other)

Categories: Status \& Trends, Action Effectiveness, Uncertainties Research

Performance Indicators and Monitored Attributes (link to ERME Program document)

Project Descriptions (objectives, methods [briefly], and types of data)

Gap Analysis (relative to the RME Program document and ERME Proposed Action)

Summary

Chapter 4 - Synthesis of Major Findings (tie all agency/program RME results together)

Introduction 
Major Findings (include published and unpublished results to the extent possible)

Synthesis

Chapter 5 - Assessment (gap analysis, i.e., how well is the RME meeting management needs?)

Introduction

Implications of RME findings for federal project design

Implications of RME findings for federal program development \& management

Evaluation of Information Dissemination/Sharing/Management

Gap Analysis

Adaptive Management Needs (summary of how RME findings in the report should affect federal estuary program and project actions)

Chapter 6 - Conclusions and Recommendations

Chapter 7 - References

\subsection{Estuary RME Plan (WE 174)}

From FY05 to FY07, we received comments from numerous reviewers, including the ISRP. The reviewers generally supported the ecosystem basis, structure, and content of the ERME Program document. Some of their major concerns included unclear programmatic goals, objectives that were inconsistent and sometimes could not be measured, weak development and application of the conceptual ecosystem model, ineffectual performance indicators, lack of prioritization of monitored attributes, underdeveloped sampling designs, and no apparent standard monitoring protocols. Furthermore, the section containing the actions recommended to implement the ERME Program needed more specifics. For example, exactly how would the adaptive management process work and who would be in charge? During 2007 and 2008, we revised the federal ERME Program document based on reviewer comments and ERME provisions in the Biological Assessment for FCRPS operations. The EOS planning effort culminated in the document Research, Monitoring, and Evaluation for Federal Estuary Program (Johnson et al. 2008).

\subsection{Status Reports (WE 185)}

Status reports on Project 2002-077-00 were submitted quarterly by PNNL to BPA in FY08 by G. Johnson. They describe the activities and accomplishments for a given month and planned activities for the next month. In FY09, project status reports will continue to be produced quarterly.

\subsection{Accomplishments and Recommendations}

During FY08, EOS accomplishments relative to BPA Project 2002-077-00 were as follows (major contributions are italicized):

- Continued facilitation and coordination of the EOS as it worked to respond to reviewer comments on the federal ERME Program document, initiated implementation of provisions in the document, and provided input to the broader federal RME effort. 
- Tracked RME efforts related to federal RME in the estuary (e.g., NED, Collaborative System-Wide Monitoring and Evaluation Project, Estuary Module, PNAMP, tributary RME, conferences and meetings, estuary restoration projects, and research and monitoring).

- Refreshed data on Project 2002-077-00 in BPA's project tracking system, Pisces, including quarterly status reports describing project activities, accomplishments, and planned tasks.

- Delivered the federal ERME Program document to BPA (January 2008) addressing reviewer comments and updates reflecting ERME in the Biological Assessment for FCRPS operations.

- Spearheaded the Columbia River Estuary Conference (CREC) during April 29-30, 2008 at the Liberty Theater in Astoria, Oregon, attended by about 150 scientists, policy-makers, resource managers, and the public.

The following activities, organized by work element, are recommended for FY09 under Project 2002-077-00 (new activities are italicized)

$\underline{\text { Work Element } 119 \text { - Manage and Administer Projects }}$

Manage and administer the project according to BPA's "Work Element/Milestone"-based project management and reporting system (Pisces).

Work Element 132 - Produce Annual Report

Produce an annual report of project activities, including (under separate cover) a pilot synthesis report of estuary/ocean RME as part of adaptive management at the program level.

Work Element 174 - Produce Plan

Revise the ERME Program document (dated January 2008) as required by the Action Agencies as new information becomes available concerning RME in the CRE.

$\underline{\text { Work Element } 185 \text { - Produce Status Report }}$

Produce quarterly status reports and upload them to Pisces.

Work Element 191 - Watershed Coordination

Much of the scope of work for Project No. 2002-077-00 is coordination of RME activities in the lower Columbia River, estuary, and ocean, as follows:

- Estuary/Ocean Subgroup for Federal RME - Continue to facilitate the EOS in its mission to implement the ERME Program.

- PNAMP Estuary Work Group - Participate in work group meetings and assist in the development of coordinated estuary planning and monitoring approaches within PNAMP.

- Federal RME Technical/Policy Oversight Group - Attend meetings and provide EOS status reports as required. 
- Technical Group for Survival Benefits - Help the Action Agencies establish this technical group and convene periodic meetings to assess survival benefits from habitat restoration.

- ERME Coordination - Work with the Action Agencies, the EP, and others to convene annual estuary $R M E$ meetings of researchers and managers to present new data, exchange information, evaluate the conduct of the ERME Program, and provide input to a pilot synthesis report for estuary/ocean RME.

- Strategic Ecosystem Restoration Approach - Attend and contribute to meetings of a new Action Agency work group intended to develop a new strategy to restoration project prioritization and selection.

\subsection{References}

Berquam, TB, BD Ebberts, and J Wilcox. 2003. Action Plan to Implement the FCRPS Biological Opinion in the Columbia River Estuary. Prepared by the U.S. Army Corps of Engineers, Portland District, Portland, Oregon. September 30, 2003.

Bottom, DL, KK Jones, and JJ Herring. 1984. Fishes of the Columbia River Estuary. Columbia River Data Development Program, Columbia River Estuary Study Taskforce, Astoria, Oregon.

Bottom, DL, CA Simenstad, J Burke, AM Baptista, DA Jay, KK Jones, E Casillas, and MH Schiewe. 2005. Salmon at River's End: The Role of the Estuary in the Decline and Recovery of Columbia River Salmon. NOAA Technical Memorandum NOAA Fisheries-NWFSC-68, Northwest Fisheries Science Center, Seattle, Washington.

Columbia River Estuary Data Development Program (CREDDP). 1984a. Index to CREDDP Data. Compiled by HT Mercier; S. Bell, ed., Columbia River Estuary Study Taskforce, Astoria, Oregon.

Columbia River Estuary Data Development Program (CREDDP). 1984b. Abstracts of Major CREDDP Publications. Compiled by D Fox, Columbia River Estuary Study Taskforce, Astoria, Oregon.

Dawley, EM, RD Ledgerwood, and AL Jensen. 1985a. Beach and Purse Seine Sampling of Juvenile Salmonids in the Columbia River Estuary and Ocean Plume, 1977-1983; Volume I; Procedures, Sampling Effort and Catch Data. NOAA Technical Memorandum. NOAA Fisheries, F/NWC-74:1260, Seattle, Washington.

Dawley, EM, RD Ledgerwood, and AL Jensen. 1985b. Beach and Purse Seine Sampling of Juvenile Salmonids in the Columbia River Estuary and Ocean Plume, 1977-1983; Volume II; Data on Marked Fish Recoveries. NOAA Tech. Memo. NOAA Fisheries, F/NWC-75:1-397, Seattle, Washington.

Dawley, EM, RD Ledgerwood, TH Blahm, CW Sims, JT Durkin, RA Kirn, AE Rankis, GE Monan, and FJ Ossiander. 1986. Migrational Characteristics, Biological Observations, and Relative Survival of Juvenile Salmonids Entering the Columbia River Estuary, 1966-1983. Prepared by the NOAA Fisheries, Northwest Fisheries Science Center, Seattle, Washington. 
Dyer, KR and RJ Orth (eds.). 1994. Changes in Fluxes in Estuaries: Implications from Science to Management. Proceedings of ECSA22/ERF Symposium, 13-18 September 1992, Institute of Marine Studies, University of Plymouth. Olsen \& Olsen, Fredensborg.

Fresh, K, E Casillas, L Johnson, and D Bottom. 2005. Role of the Estuary in the Recovery Columbia River Basin Salmon and Steelhead: An Evaluation of Selected Factors on Salmonid Population Viability. NOAA Technical Memorandum NMFS-NWFSC-69, NOAA Fisheries, Northwest Fisheries Science Center, Seattle, Washington.

Johnson, G. 2005. Estuary/Ocean Research, Monitoring, and Evaluation Support Project: FY05 Annual Report. Final report by the Pacific Northwest National Laboratory, Richland, Washington, for the Bonneville Power Administration, Portland, Oregon.

Johnson, G. 2006. Facilitation of the Estuary/Ocean Subgroup for Research, Monitoring, and Evaluation, FY06 Annual Report. PNNL-16142, final report by the Pacific Northwest National Laboratory, Richland, Washington, for the Bonneville Power Administration, Portland, Oregon.

Johnson, GE and HL Diefenderfer. 2007. Facilitation of the Estuary/Ocean Subgroup for Research, Monitoring, and Evaluation, FY07 Annual Report. PNNL-16947, final report by the Pacific Northwest National Laboratory, Richland, Washington, for the Bonneville Power Administration, Portland, Oregon.

Johnson, GE and HL Diefenderfer (eds.). 2008. Evaluating Cumulative Ecosystem Response to Restoration Projects in the Columbia River Estuary, Annual Report 2007. PNNL-16561, draft report by the Pacific Northwest National Laboratory, Richland, Washington for the U.S. Army Corps of Engineers, Portland District, Portland, Oregon.

Johnson, GE and GB Sutherland (eds.). 2006. Conference on Research, Monitoring, and Restoration in the Lower Columbia River, Estuary, and Nearshore Ocean. Proceedings compiled by Pacific Northwest National Laboratory, Richland, Washington. Available at http://cerc.labworks.org/.

Johnson, GE and GB Sutherland (eds.). 2008. Proceedings of the Columbia River Estuary Conference on Ecosystem Restoration. Compiled by Pacific Northwest National Laboratory, Richland, Washington. Available at http://cerc.labworks.org/.

Johnson, GE, RM Thom, AH Whiting, GB Sutherland, T Berquam, BD Ebberts, NM Ricci, JA Southard, and JD Wilcox. 2003. An Ecosystem-Based Approach to Habitat Restoration Projects with Emphasis on Salmonids in the Columbia River Estuary. PNNL-14412, final report by the Pacific Northwest National Laboratory, Richland, Washington, for the Bonneville Power Administration, Portland, Oregon..

Johnson, GE, HL Diefenderfer, BD Ebberts, C Tortorici, T Yerxa, J Leary, and J Skalski. 2008. Research Monitoring and Evaluation for the Federal Columbia River Estuary Program. PNNL-17300, final report by the Pacific Northwest National Laboratory, Richland, Washington, for the Bonneville Power Administration, Portland, Oregon. 
Jordan, C, J Geiselman, M Newsom, and J Athearn (eds.). 2003. Research, Monitoring \& Evaluation Plan for the NOAA-Fisheries 2000 Federal Columbia River Power System Biological Opinion. Draft dated September 11, 2003. NOAA Fisheries, Bonneville Power Administration, U.S. Army Corps of Engineers, and Bureau of Reclamation.

Kirn, RA, RD Ledgerwood, and AL Jensen. 1986. "Diet of Subyearling Chinook Salmon (Oncorhynchus tshawytscha) in the Columbia River Estuary and Changes Effected by the 1980 Eruption of Mount St. Helens." Northwest Science 60:191-196.

Ledgerwood, RD, FP Thrower, and EM Dawley. 1991. "Diel sampling of migratory juvenile salmonids in the Columbia River estuary." Fisheries Bulletin 89:69-78.

Lower Columbia River Estuary Partnership and Lower Columbia Fish Recovery Board. 2004a. Lower Columbia Salmon and Steelhead Recovery and Subbasin Plan. Volume I and II. Report prepared for the Northwest Power and Conservation Council, May 28, 2004. Available at http://www.nwcouncil.org/fw/subbasinplanning/lowerColumbia/plan/.

Lower Columbia River Estuary Partnership and Lower Columbia Fish Recovery Board. 2004b. Supplement to the Mainstem Lower Columbia River and Columbia River Estuary Subbasin Plan. Prepared for the Northwest Power and Conservation Council, November 22, 2004. Available at http://www.lcrep.org/pdfs

Lower Columbia River Estuary Program (now called Partnership). 1999. Lower Columbia River Estuary Plan, Comprehensive Conservation and Management Plan. Volume I. Portland, Oregon.

McCabe, GT Jr, WD Muir, and JT Durkin. 1983. "Interrelationships between juvenile salmonids and nonsalmonid fish in the Columbia River Estuary." U.S. Bur. Fish. Bull. 81:815-826.

McCabe, GT Jr, RL Emmett, WD Muir, and TH Blahm. 1986. Utilization of the Columbia River Estuary by Subyearling Chinook Salmon. Northwest Science, 60(2):113-124.

McConnell, R, T Blahm, G McCabe, T Clocksin, T Coley, J Durkin, R Emmett, and W Muir. 1983. Columbia River Estuary Data Development Program Data Report: Salmonid and Non-Salmonid Fish, four volumes. Columbia River Estuary Data Development Program, managed by Columbia River Estuary Taskforce, Astoria, Oregon.

National Oceanic and Atmospheric Administration (NOAA) Fisheries. 2008. Biological OpinionConsultation on Remand for Operation of the Federal Columbia River Power System, 11 Bureau of Reclamation Projects in the Columbia Basin and ESA Section 10(a)(1)(A) Permit for Juvenile Fish Transportation Program. National Marine Fisheries Service (NOAA Fisheries) - Northwest Region. Seattle, Washington.

Pacific Northwest Aquatic Monitoring Partnership (PNAMP). 2004. Recommendations for Coordinating State, Federal, and Tribal Watershed and Salmon Monitoring Programs in the Pacific Northwest. Prepared by the Pacific Northwest Aquatic Monitoring Partnership, Portland, Oregon.

Pruter, AT and DL Alverson (eds.). 1972. The Columbia River Estuary and Adjacent Ocean Waters: Bioenvironmental Studies. University of Washington Press, Seattle, Washington. 
Reimers, PE and RE Loeffel. 1967. "The Length of Residence of Juvenile Fall Chinook Salmon in Selected Columbia River Tributaries.” Res. Briefs, Fish Comm. Oreg. 13(1):5-19

Rich, WH. 1920. "Early history and seaward migration of Chinook salmon in the Columbia and Sacramento rivers." U.S. Bur. Fish. Bull. 37:2-73.

Roegner, GC, HL Diefenderfer, AB Borde, RM Thom, EM Dawley, AH Whiting, SA Zimmerman, and GE Johnson. 2008. Protocols for Monitoring Habitat Restoration Projects in the Lower Columbia River and Estuary. PNNL-15793, Prepared by NOAA Fisheries, Hammond, Oregon, and Pacific Northwest National Laboratory, Richland, Washington, for the U.S. Army Corps of Engineers, Portland District, Portland, Oregon.

Small, LF (ed.). 1990. “Columbia River: Estuarine System.” Progress in Oceanography 25(1-4).

U.S. Army Corps of Engineers (USACE). 2001. Biological Assessment Columbia River Channel Improvements Project. Prepared by the U.S. Army Corps of Engineers for NOAA Fisheries and U.S. Fish and Wildlife Service, Portland, Oregon. 



\section{Distribution}

No. of

Copies

Catherine Corbett

Lower Columbia River Estuary

Partnership

811 SW Naito Parkway, Suite 120

Portland, Oregon 97204

Anne Creason

Bonneville Power Administration

PO Box 3621

Portland, Oregon 97208

Blaine Ebberts

US Army Corps of Engineers

333 SW First Avenue

Portland, Oregon 97204

Jim Geiselman

Bonneville Power Administration

PO Box 3621

Portland, Oregon 97208

Chris Hathaway

Lower Columbia River Estuary Partnership

811 SW Naito Parkway, Suite 120

Portland, Oregon 97204
No. of

Copies

Krista Jones

Lower Columbia River Estuary

Partnership

811 SW Naito Parkway, Suite 120

Portland, Oregon 97204

Doug Putman

US Army Corps of Engineers

333 SW First Avenue

Portland, Oregon 97204

Cathy Tortorici

NOAA Fisheries

1201 NE Lloyd Blvd.

Portland, Oregon 97232

Tracey Yerxa

Bonneville Power Administration

PO Box 3621

Portland, Oregon 97208

2 Local Distribution

Pacific Northwest National Laboratory

Gary Johnson

$\mathrm{BPO}$

Heida Diefenderfer

SEQUIM 


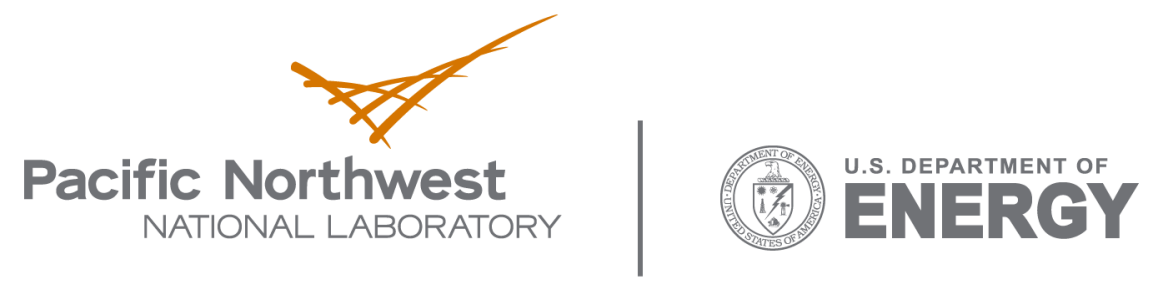

902 Battelle Boulevard

P.O. Box 999

Richland, WA 99352

1-888-375-PNNL (7665)

www.pnl.gov 